\title{
Gemcitabine-mediated tumour regression and p53-dependent gene expression: implications for colon and pancreatic cancer therapy
}

\author{
R Hill ${ }^{1,2,6}$, M Rabb ${ }^{2}$, PA Madureira ${ }^{1}$, D Clements ${ }^{3}$, SA Gujar ${ }^{2}$, DM Waisman ${ }^{4}$, CA Giacomantonio ${ }^{3,4,5}$ and PW K Lee ${ }^{*, 1,2,3}$
}

Gemcitabine is a chemotherapeutic that is widely used for the treatment of a variety of haematological malignancies and has become the standard chemotherapy for the treatment of advanced pancreatic cancer. Combinational gemcitabine regimes (e.g.with doxorubicin) are being tested in clinical trials to treat a variety of cancers, including colon cancer. The limited success of these trials has prompted us to pursue a better understanding of gemcitabine's mechanism of cell killing, which could dramatically improve the therapeutic potential of this agent. For comparison, we included gamma irradiation that triggers robust cell cycle arrest and $\mathrm{Cr}(\mathrm{VI})$, which is a highly toxic chemical that induces a robust p53-dependent apoptotic response. Gemcitabine induced a potent p53-dependent apoptosis that correlated with the accumulation of pro-apoptotic proteins such as PUMA and Bax. This is accompanied by a drastic reduction in p2I and 14-3-3 $\sigma$ protein levels, thereby significantly sensitizing the cells to apoptosis. In vitro and in vivo studies demonstrated that gemcitabine required PUMA transcription to instigate an apoptotic programme. This was in contrast to $\mathrm{Cr}(\mathrm{VI})$-induced apoptosis that required Bax and was independent of transcription. An examination of clinical colon and pancreatic cancer tissues shows higher p53, p21, 14-3-3 $\sigma$ and Bax expression compared with matched normal tissues, yet there is a near absence of PUMA protein. This may explain why gemcitabine shows only limited efficacy in the treatment of these cancers. Our results raise the possibility that targeting the Bax-dependent cell death pathway, rather than the PUMA pathway, could result in significantly improved patient outcome and prognosis for these cancers.

Cell Death and Disease (2013) 4, e791; doi:10.1038/cddis.2013.307; published online 5 September 2013

Subject Category: Cancer

The tumour-suppressor p53 regulates cell cycle arrest, apoptosis or senescence ${ }^{1-4}$ and is one of the most frequently mutated proteins in cancer. ${ }^{5,6}$ Cellular stress mediates p53 stabilization directing cell cycle arrest (controlled by p21 and 14-3-3 $\sigma$ ) or apoptosis (requiring PUMA, Bax, Noxa or BID). ${ }^{5,7}$

The p53-dependent expression of PUMA has been shown as a key determinant of transcription-dependent apoptosis as the phenotype of $\left[P_{U M A^{-/}}\right]$HCT116 cells are strikingly similar to that of $\left[p 53^{-/-}\right]$HCT116 cells. ${ }^{8,9}$ There is also a transcription-independent p53 response to cellular stress, ${ }^{10-12}$ whereas p53-dependent apoptosis can be readily observed in the absence of PUMA correlating with the cytosolic accumulation of p53 and activation of Bax. ${ }^{13,14}$ p53 can directly interact with Bax, mediating the latter's oligomerization inducing the permeabilization of mitochondria. Although Bax is a clear component of p53-mediated transcription-independent cell death, Bax transcription is regulated by p53, highlighting the overlap between these mechanisms to induce apoptosis. ${ }^{15}$

Most anti-cancer drugs in use today are selected on their ability to induce apoptotic cell death. Gemcitabine (a deoxycytidine analogue) has become the standard chemotherapeutic for the treatment of advanced pancreatic cancer and is currently in phase II clinical trials to treat colon cancer. ${ }^{16-18}$ There are also apoptosis-inducing chemicals including chromium $(\mathrm{Cr}(\mathrm{VI}))^{19}$ that is highly toxic introducing chromium-DNA adducts and DNA breaks. ${ }^{20-22}$

We compare gemcitabine with the $\mathrm{Cr}(\mathrm{VI})$ evaluating their mechanism of action regarding apoptosis induction. We demonstrate that gemcitabine-induced apoptosis is mediated in a p53 transcription- and PUMA-dependent manner. $\mathrm{Cr}(\mathrm{VI})$ exposure mediates a potent p53-dependent apoptotic effect that is transcription-independent but required the protein Bax. For both, there is the requirement for the loss of p21 and/ or 14-3-3 $\sigma$ prior to the induction of apoptosis, whereas the loss of either prior to treatment significantly increased sensitivity to each compound. Although these compounds were effective in reducing tumour burden of $\left[\mathrm{p53}^{+/+}\right] \mathrm{HCT} 116$ tumours in mice, they showed differential effects on $\left[P U M A^{-/-}\right]$and $\left[\mathrm{Bax}^{-/-}\right.$] HCT116 tumours that mirrored those observed in vitro. Primary colon or pancreatic cancer patient sample analysis revealed significant p53 accumulation and activation within tumour tissues yet the striking absence of the PUMA

\footnotetext{
${ }^{1}$ Centre for Molecular and Structural Biomedicine, University of Algarve, Algarve, Portugal; ${ }^{2}$ Department of Microbiology \& Immunology, Dalhousie University, Halifax, Nova Scotia, Canada; ${ }^{3}$ Department of Pathology, Dalhousie University, Halifax, Nova Scotia, Canada; ${ }^{4}$ Department of Biochemistry and Molecular Biology, Dalhousie University, Halifax, Nova Scotia, Canada; ${ }^{5}$ Department of Surgery, Faculty of Medicine Dalhousie University, Halifax, Nova Scotia, Canada and ${ }^{6}$ Department of Medicine, University of Algarve, Algarve, Portugal

${ }^{*}$ Corresponding author: PWK Lee, Microbiology and Immunology, Dalhousie University, 5850 College Street, 7P, Charles Tupper Buildinig, Halifax, Nova Scotia B3H 1X5, Canada. Tel: +902 494 8048; Fax: +902 494 3292; E-mail: Patrick.Lee@Dal.ca

Keywords: p53; PUMA; Bax; apoptosis; gemcitabine; chromium

Abbreviations: MTS, (3-(4,5-dimethylthiazol-2-yl)-5-(3-carboxymethoxyphenyl)-2-(4-sulfophenyl)-2H-tetrazolium); IR, irradiation; SD, standard deviation; EC50, effective concentration 50\%; qRT-PCR, quantitative real time polymerase chain reaction; HIF, hypoxia induced factor; DMEM, Dulbecco's Modified Eagle Medium; FBS, fetal bovine serum; PBS, phosphate buffered saline; dsDNA, double stranded

Received 04.2.13; revised 12.7.13; accepted 15.7.13; Edited by D Aberdam
} 
protein (in contrast to Bax). As gemcitabine is currently being used to treat pancreatic and colon cancer with limited efficacy, our results raise the possibility that targeting the Baxdependent apoptotic pathway could offer significantly improved patient outcome.

\section{Results}

Cell line exposure to gemcitabine or chromium induces the accumulation of $\mathrm{p} 53$ and mediates a potent apoptotic response. To establish the cellular conditions that induced significant cell death following exposure to each agent (gemcitabine or $\mathrm{Cr}(\mathrm{VI})$ ), the $\mathrm{EC}_{50}$ values for our cell lines were determined using the MTS assay. Each compound induced significant cell death in the p53-containing cell lines but not p53-deficient cells lines at $72 \mathrm{~h}$ post treatment (Figure 1a). There was no significant change in cell line viability following $\gamma$-IR exposure (10 Gy) (data not shown). Western blot analysis of $\left[p 53^{+/+}\right]$HCT116 and U2OS cells showed that induction of cell death by these chemicals was accompanied by pronounced accumulation of p53 as well as cleaved caspase-2, caspase-3 and caspase-9 (Figure 1b). We did not detect p53 accumulation nor caspase cleavage in the $\left[p 53^{-/-}\right]$HCT116 or Saos-2 cell lines. In agreement with the immunoblot data, annexin- $V$ staining of cells $48 \mathrm{~h}$ following exposure to gemcitabine or $\mathrm{Cr}(\mathrm{VI})$, but not $\gamma-\mathrm{IR}$,

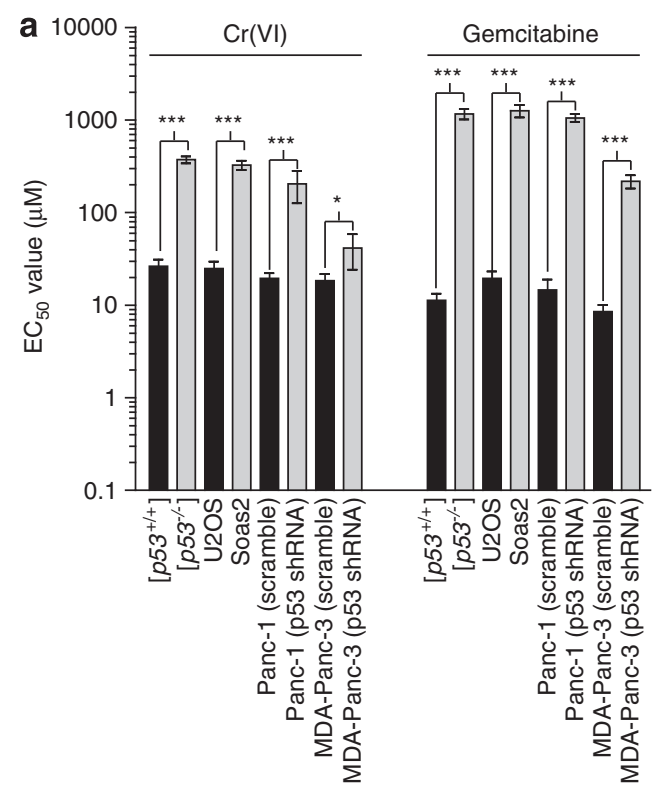

C

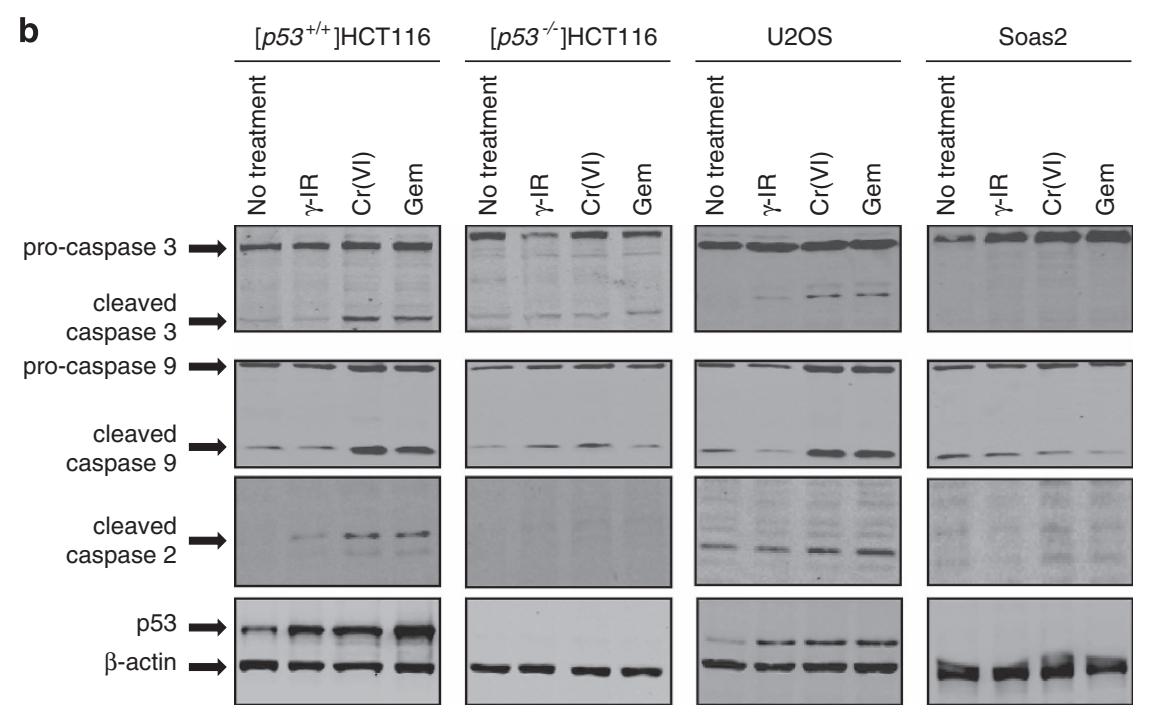

Figure 1 p53 is required for gemcitabine- and $\mathrm{Cr}(\mathrm{VI})$-mediated cell death. (a) At $72 \mathrm{~h}$ post chemical exposure, MTS assays were conducted for each cell line shown. Stable knockdown cell lines were generated using our retrovirus expression system (pSUPER-Retro) and selected and cultured in puromycin ( $2 \mu \mathrm{g} / \mathrm{ml}$ ) for the duration of our studies. Results are mean \pm S.D.; ${ }^{* \star *} P<0.0001,{ }^{*} P<0.05$. Each assay was conducted in triplicate and each set of experiments was repeated three times. (b) Cell lines were treated $(10 \mu \mathrm{M}$ Gemcitabine, $30 \mu \mathrm{M} \mathrm{Cr}(\mathrm{VI})$ or $10 \mathrm{~Gy} \gamma-\mathrm{IR})$ for $48 \mathrm{~h}$ and lysates were prepared and subjected to SDS-PAGE. Immunoblotting was carried out using caspase-3, caspase9 , caspase-2, p53 and $\beta$-actin antibodies. (c) At $48 \mathrm{~h}$ post DNA damage, annexin-V staining was carried out following the manufacturer's guidelines. The percentage of positive cells was determined by FACS analysis (Becton Dickinson, Franklin Lakes, NJ, USA). Results are mean \pm S.D. $n=3$ 
showed increased annexin- $V$ staining in cells containing p53 (Figure 1c).

Each DNA damage agent induces the accumulation of p53-regulated pro-apoptotic proteins. We investigated if there was any difference between these agents in inducing

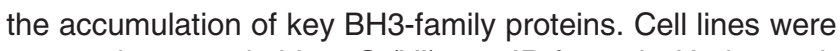
exposed to gemcitabine, $\mathrm{Cr}(\mathrm{VI})$ or $\gamma$-IR for $48 \mathrm{~h}$. Under each damage condition, we observe accumulation of PUMA and Bax proteins in p53-containing cell lines (Figure 2a). Consistent with the induction of apoptosis there was significant BID accumulation and cleavage, particularly in

a

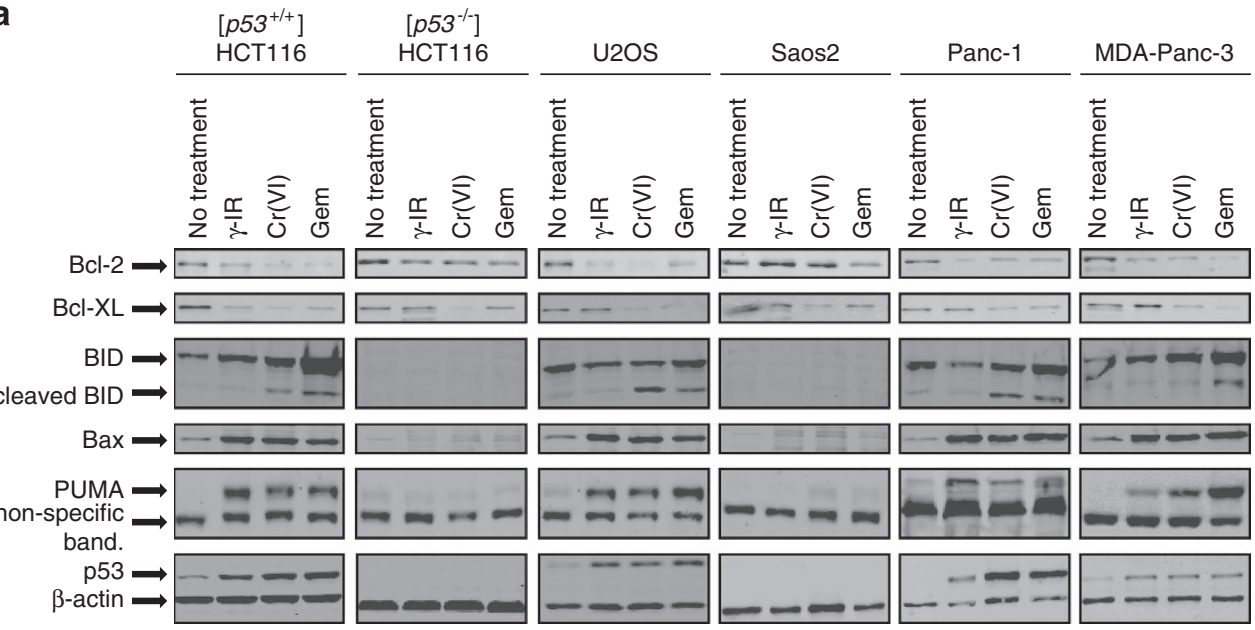

b
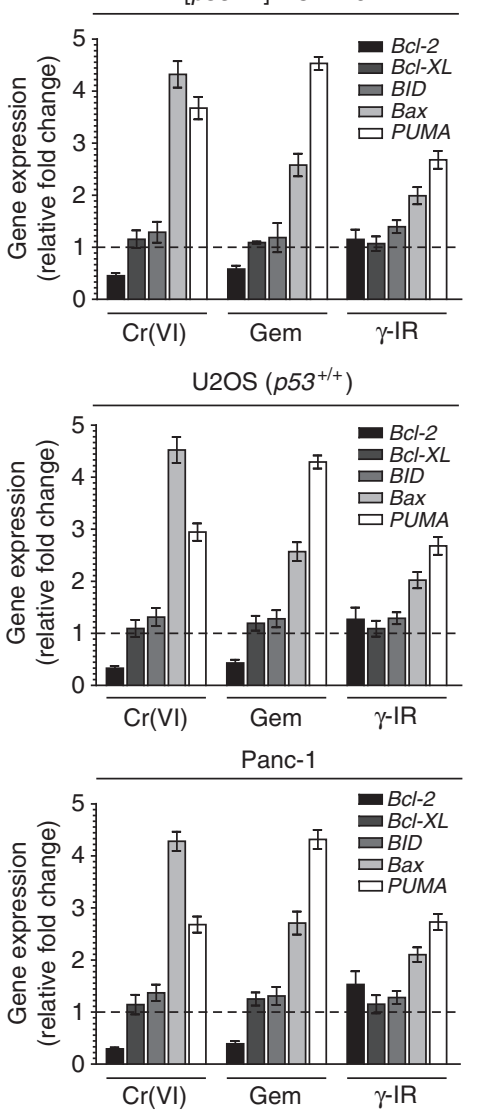
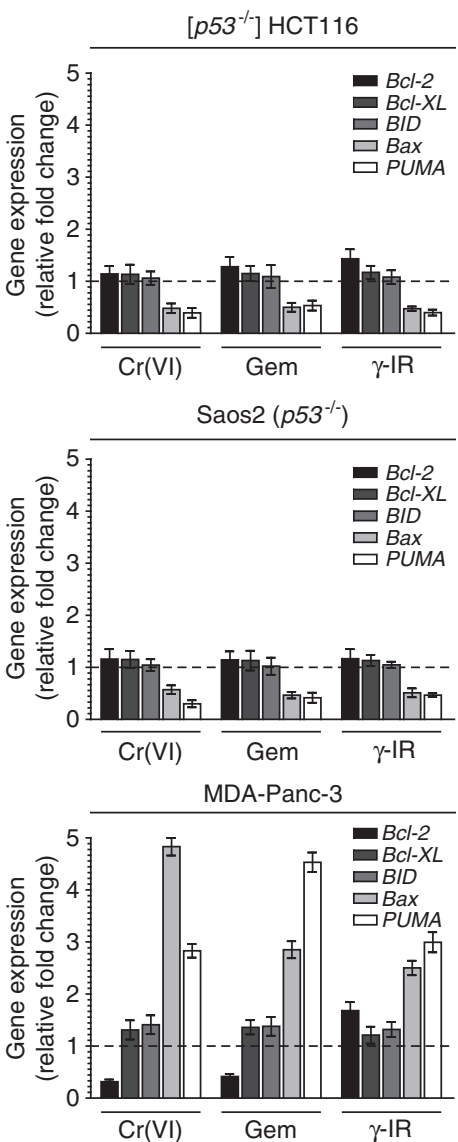

Figure 2 BH3-family transcription and translation is conserved regardless of damage modality. (a) Indicated cell lines were exposed to gemcitabine (10 $\mu \mathrm{M})$, $\mathrm{Cr}(\mathrm{VI})$ $(30 \mu \mathrm{M})$ or $\gamma-\mathrm{IR}(10 \mathrm{~Gy})$ for $48 \mathrm{~h}$. Immunoblotting was carried out for Bcl-2, Bcl-xL, Bid, Bax, PUMA, p53 and $\beta$-actin. (b) Cells were treated as indicated and RNA was extracted using Trizol (Invitrogen). cDNA was generated (superscript II, Invitrogen) and qRT-PCR (Sybr Green, Stratagene) was carried out for Bcl-2, Bcl-xL, Bid, Bax, PUMA and $G A P D H$. Expression was normalized to GAPDH and gene expression (fold change) was calculated using the $2^{-\triangle \triangle C T}$ formula. Each assay was conducted in quadruplicate, $N=3$ 
cells exposed to gemcitabine or $\mathrm{Cr}(\mathrm{VI})$. A reduction in the level of the anti-apoptotic proteins $\mathrm{Bcl}-2$ and $\mathrm{Bcl}-\mathrm{xL}$ was also evident in these treated cells. Overall, gemcitabine and $\mathrm{Cr}(\mathrm{VI})$ treatment greatly altered the ratios of pro-apoptotic proteins (Bax/PUMA/cleaved BID) to anti-apoptotic proteins (Bcl-2/Bcl-xL) in p53-containg cells.

To determine if the protein level correlated with gene transcription, we conducted a quantitative real time PCR screen (Figure 2b). There was the induction of PUMA and Bax in all p53-containing cells exposed to any of the treatments. We did not observe a significant change in Bid transcription suggesting that BID stabilization and cleavage was important for its apoptotic function after treatment. In cells exposed to $\mathrm{Cr}(\mathrm{VI})$ or gemcitabine, the $\mathrm{Bcl}-2$ and $\mathrm{Bcl}-x \mathrm{~L}$ expression levels were either reduced $(B c l-2)$ or remained unchanged $(B c l-x L)$. In contrast (and in agreement with the immunoblot data), for both the [p53-/- ] HCT116 and the Saos-2 cell lines, there was significantly reduced expression of PUMA and Bax, but no change in $\mathrm{Bcl}-2$ or $\mathrm{Bcl}-x \mathrm{~L}$ expression. It is interesting that $\gamma$-IR that promotes cell growth arrest (but not apoptosis) generated similar $\mathrm{BH}$-family gene expression profiles.

Reduction of $p 21$ and 14-3-3 $\sigma$ correlates with the induction of apoptosis following DNA damage and the loss of both synergistically increases this sensitivity. Following our BH3-family expression screen, we examined both the protein levels and the transcript levels of the cyclindependent inhibitor $1 \mathrm{~A}$ (p21) and the cell cycle arrest protein 14-3-3 $\sigma$, (both key p53-regulated proteins) and protect cells from p53-dependent apoptosis. ${ }^{23-28}$ Whereas exposure to $\gamma-\mathrm{IR}$ resulted in elevated $p 21$ and $14-3-3 \sigma$ expression at both the transcript and protein levels (Figures $3 a$ and $b$ ), gemcitabine and $\mathrm{Cr}(\mathrm{VI})$ displayed significant suppression of expression and a corresponding lowered protein level of these two genes. Although the loss of p21 mRNA expression following chromium exposure has previously been reported, ${ }^{29,30}$ the observation that the chemotherapeutic drug gemcitabine showed a similar repression of $p 21$ expression was revealing, particularly when one considers that the expression of the 14-3-3 $\sigma$ protein, which complements p21 in blocking cell progression at $G_{2}$, was also repressed.

We questioned if the knockout or knockdown of either p21 or 14-3-3 $\sigma$ would enhance the sensitivity of p53-containing cells to these drugs. Our data (Figure $3 c$ ) clearly showed that knockout or the knockdown of p21 or 14-3-3 $\sigma$ significantly increased the sensitivity of wild-type p53-containing cells to gemcitabine and $\mathrm{Cr}(\mathrm{VI})$ and the double knockout $\left[p 21^{-/-}\right]\left[14-3-3 \sigma^{-/-}\right]$HCT116 cells show a synergistically increased sensitivity to gemcitabine and $\mathrm{Cr}(\mathrm{VI})$ compared with either single knockout. Exposure of these knockdown or knockout cell lines to $\gamma$-IR failed to significantly increase cell death even at the highest $\gamma$-IR doses investigated (data not shown).

Gemcitabine requires transcription to trigger apoptosis in contrast to $\mathrm{Cr}(\mathrm{VI})$. Gemcitabine and $\mathrm{Cr}(\mathrm{VI})$ both induced p53-dependent cell death (Figure 1) and each significantly increased the transcription of the pro-apoptotic genes Bax and PUMA (Figure 2), we questioned if cell line sensitivity was affected if transcription was inhibited. Each cell line was pretreated with actinomycin D inhibiting transcription. ${ }^{31-33}$ We observed significantly increased cell line resistance to gemcitabine, generating EC50 values that were similar to those from cell lines that lack p53 (Figure 4a). Cr(VI)-induced cell death was transcription-independent.

We examined the protein expression profile of p53 and p53-regulated genes when transcription was inhibited (Figure 4b). Transcription inhibition of gemcitabine-treated cells blocked the accumulation of both pro-growth arrest proteins (p21 and 14-3-3 $\sigma$ ) and pro-apoptotic proteins (Bax and PUMA). After $\mathrm{Cr}(\mathrm{VI})$ exposure, there was little to no reduction in the protein level of Bax despite the continued presence of actinomycin D, a response conserved in a range of cell lines, suggesting that in contrast to gemcitabine, pre-existing Bax could be stabilized following $\mathrm{Cr}(\mathrm{VI})$ exposure, although the exact mechanism controlling this is currently unknown.

A key characteristic of transcription-independent apoptosis involves the shuttling of p53 into the cytoplasm. We investigated the distribution of p53 within our cell lines following exposure to each agent. In contrast to gemcitabine (where the majority of p53 was nuclear), $\mathrm{Cr}(\mathrm{VI})$ exposure induced significant accumulation of p53 in the cytoplasm (Figure 4c). This supports the observation shown in Figure 4a that following gemcitabine exposure, p53 mediates its cellular effect at the transcription level, whereas $\mathrm{Cr}(\mathrm{VI})$ induces p53-dependent apoptosis in a transcription-independent manner. $\gamma \mathrm{IR}$ treatment promoted significant nuclear accumulation of p53 consistent with a potent p21-dependent cell cycle arrest phenotype.

Gemcitabine-induced apoptosis is PUMA-dependent, whereas $\mathrm{Cr}(\mathrm{VI})$-induced apoptosis is Bax-dependent. We questioned if the different modes of induction of these pro-apoptotic $\mathrm{BH} 3$ proteins reflected actual differences in apoptotic outcome. [PUMA $\left.{ }^{-/-}\right]$or $\left[\mathrm{Bax}^{-/-}\right]$HCT116 cells were treated and MTS cell viability assays were carried out (Figure 5a). The [PUMA $\left.{ }^{-1-}\right]$ HCT116 cells (compared with $\left[\mathrm{Bax}^{-/-}\right] \mathrm{HCT} 116$ cells), had a significantly higher $\mathrm{EC}_{50}$ value (and thus are considerably more resistant) to gemcitabine treatment $72 \mathrm{~h}$ post drug exposure. In contrast, $\mathrm{Cr}(\mathrm{VI})$ induced apoptosis was not affected by the PUMA status within the cell, but was significantly attenuated in the absence of Bax. Similarly, shRNA knockdown of either PUMA or Bax induced a similar differential response to each agent (Figure 5a). The restoration of PUMA or Bax expression in either knockout cell lines rescued each phenotype and generated, $72 \mathrm{~h}$ post treatment, $\mathrm{EC}_{50}$ values similar to wild-type cells (Figure $5 \mathrm{~b}$ ). These findings support the notion that although the loss of p21 or 14-3-3 $\sigma$ significantly enhances cellular susceptibility to stress, distinct p53-effector pro-apoptotic proteins are critical to instigate these responses.

In vivo tumour regression after gemcitabine treatment is PUMA-dependent. Our in vitro studies indicate that when cell lines are exposed to gemcitabine they induce p53dependent apoptosis contingent upon the transcriptional expression of PUMA. In contrast, $\mathrm{Cr}(\mathrm{VI})$ mediates transcription-independent cell death and requires only the presence 

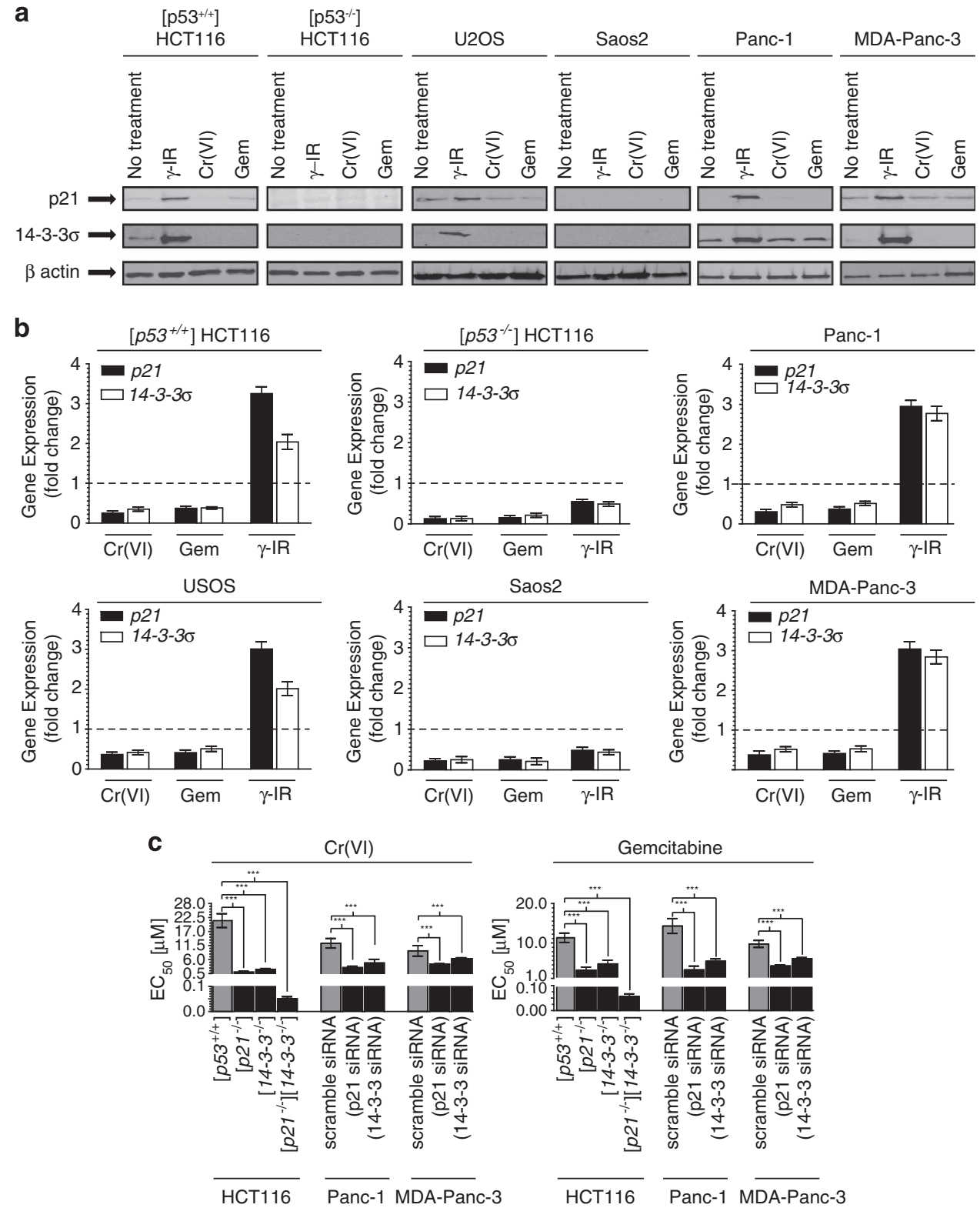

Figure 3 Differential expression of $p 21$ and 14-3-3 $\sigma$ affects sensitivity to chemotherapeutics. (a) Indicated cell lines were exposed to gemcitabine (10 $\mu \mathrm{M}), \mathrm{Cr}(\mathrm{VI})(30 \mu \mathrm{M})$ or $\gamma-\mathrm{IR}$ (10 Gy) for $48 \mathrm{~h}$. Immunoblotting was carried out for p21, 14-3-3 $\sigma$ and $\beta$-actin. (b) Cells were treated as indicated and qRT-PCR was carried out $24 \mathrm{~h}$ post damage for p21, 14-3-3 $\sigma$ and GAPDH. Each assay was conducted in quadruplicate and each set of experiments was repeated three times. (c) The viability of cell lines with p21 or 14-3-3 $\sigma$ knocked out or knocked down was measured after $72 \mathrm{~h}$ exposure to the indicated DNA-damaging agents. Results are mean \pm S.D.; ${ }^{* * *} P<0.0001$. Each assay was conducted in triplicate, $N=3$

of the p53 and Bax protein. We questioned if this could be demonstrated in vivo and if these DNA-damaging agents could trigger regression in established tumours. $\left[p 53^{+/+}\right]$HCT116 tumours were subcutaneously established in the flanks of NOD/SCID mice and injected intratumourally with gemcitabine $(30 \mathrm{mg} / \mathrm{kg}$ in $50 \mu \mathrm{l}$ based on average tumour weight) or $\mathrm{Cr}(\mathrm{VI})(10 \mathrm{mg} / \mathrm{kg}$ in $50 \mu \mathrm{l}$ based on average tumour

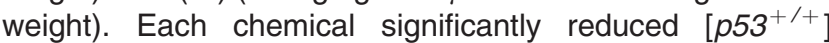
tumour volume 21 days post injection but had no effect on $\left[p 53^{-/-}\right]$HCT116 tumours (Figure 6a), supporting our in vitro data. With each treatment regime, we noted no associated toxicity or adverse effects. As expected, each control group (50 $\mu$ PBS) showed significant, rapid tumour growth over the same time period.

To confirm the role(s) of PUMA and Bax following exposure to each DNA-damaging agent, we repeated our in vivo studies using the matched $[\mathrm{Bax}-/-]$ and [PUMA $-/-]$ HCT116 cell lines. We note that $\left[P \cup M A^{-/-}\right]$tumours underwent significant regression after $\mathrm{Cr}(\mathrm{VI})$ treatment consistent with the wildtype HCT116 tumours (Figure 6b); however, unlike wild-type tumours, the $\left[P U M A^{-/-}\right]$tumours were resistant to gemcitabine. The opposite results were obtained when $\left[\mathrm{Bax}^{-1-}\right] \mathrm{HCT} 116$ 

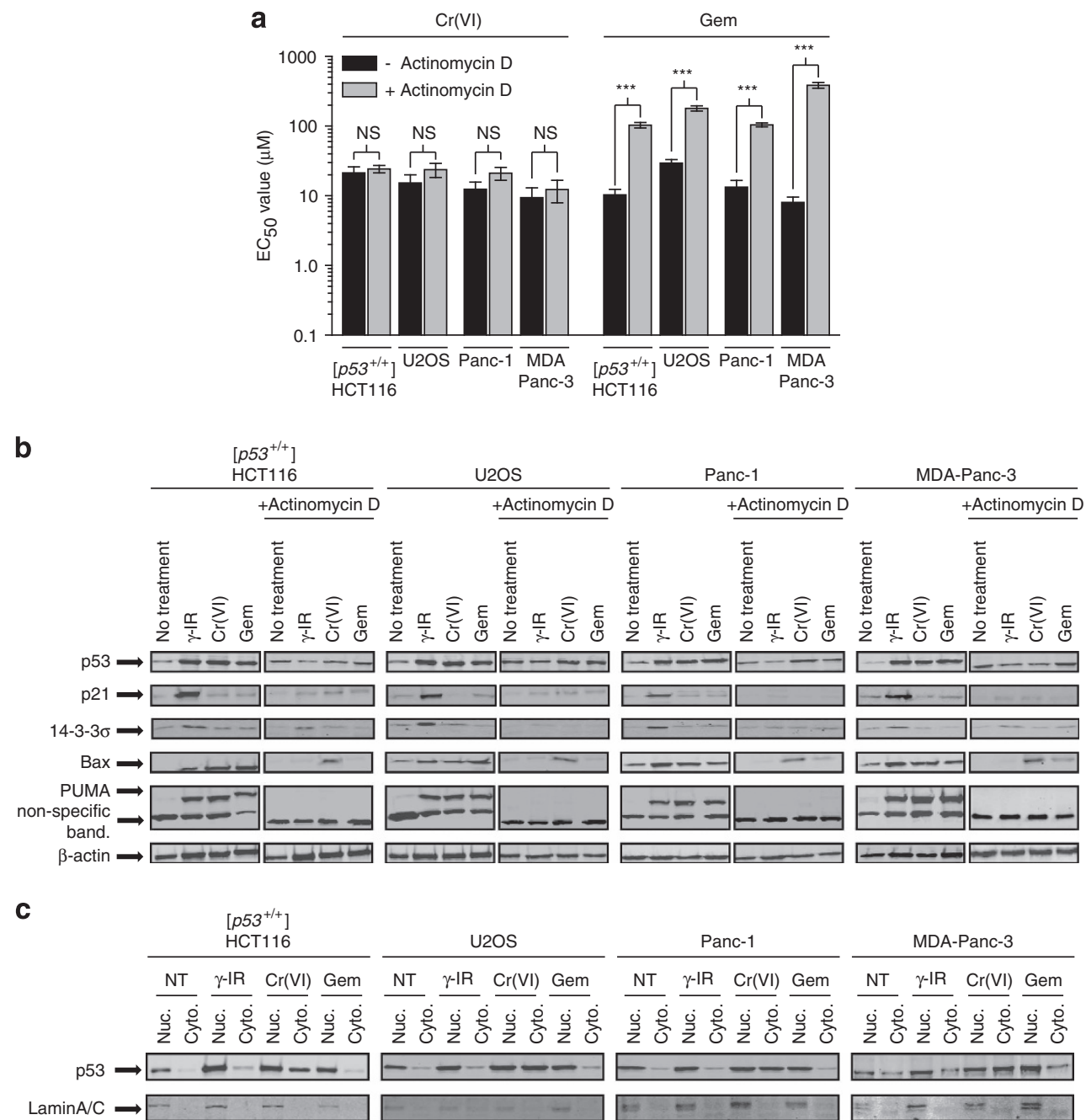

Figure 4 Gemcitabine induces cell death in a transcription-dependent manner. (a) Cell lines indicated were mock/pretreated with actinomycin D (1 $\mu \mathrm{g} / \mathrm{ml})$ for $6 \mathrm{~h}$. At $72 \mathrm{~h}$ MTS assays were conducted for the indicated DNA-damaging agents in the presence of actinomycin D. $N=3$. Results are mean \pm S.D.; ${ }^{* \star} P<0.0001$. (b) Indicated cell lines were mock/pretreated with actinomycin $\mathrm{D}(1 \mu \mathrm{g} / \mathrm{ml})$ and exposed to gemcitabine $(10 \mu \mathrm{M}), \mathrm{Cr}(\mathrm{VI})(30 \mu \mathrm{M})$ or $\gamma-\mathrm{IR}(10 \mathrm{~Gy})$ for $48 \mathrm{~h}$. Immunoblotting was carried out for p53, p21, 14-3-3 $\sigma$, Bax, PUMA and $\beta$-actin. (c) Indicated cell lines were treated as described in $\mathbf{b}$. Nuclear and cytoplasmic fractions were collected and immunoblotting was carried out for total p53, actin and Lamin A/C

tumours were treated, where gemcitabine triggered the significant reduction of these tumours over the 21 day period in contrast to $\mathrm{Cr}(\mathrm{VI})$, which had no significant effect.

To further confirm our in vitro results, we collected the tumours 21 days post treatment from each wild-type HCT116 group and measured the protein levels of p53, p21, 14-3-3 $\sigma$, Bax and PUMA (Figure 6c). In contrast to the untreated control tumours, both the $\mathrm{Cr}(\mathrm{VI})$ - and the gemcitabine-treated tumours showed significant p53, Bax and PUMA protein accumulation consistent with our previously described in vitro studies. As predicted from our in vitro studies, there was the loss of both the p21 and 14-3-3 $\sigma$ proteins following either DNA-damaging regime. Collectively, these studies show that gemcitabine-mediated tumour regression is PUMA-dependent but Bax-independent, whereas $\mathrm{Cr}(\mathrm{VI})$-mediated tumour regression is Bax-dependent but PUMA-independent, and that both modalities ablate p21 and 14-3-3 $\sigma$ expression/ protein accumulation.
Colon and pancreatic cancer clinical samples show elevated p21 and Bax expression, but attenuated PUMA expression. Gemcitabine has been widely used to treat colon and/or pancreatic cancers, however, this treatment regiment has met with limited success in clinical trials. Colon and pancreatic cancers have been shown to contain a high percentage of p53 mutations $s^{34,35}$ and to determine whether the relatively low efficacy of this drug could be linked to the status of p53, PUMA, Bax and p21, clinical samples of colon or pancreatic cancer were subjected to hematoxylin/eosin staining and compared with matched normal tissues taken from each patient. We conducted immunofluorescence staining for annexinA2 (ANXA2) (as a predominantly cell surface protein), allowing us to identify the presence, abundance and subcellular localization of p53 within our clinical sections. All of our matched clinical samples (tumour and normal tissue) were obtained during conventional surgical intervention and, importantly, none of our cancer 

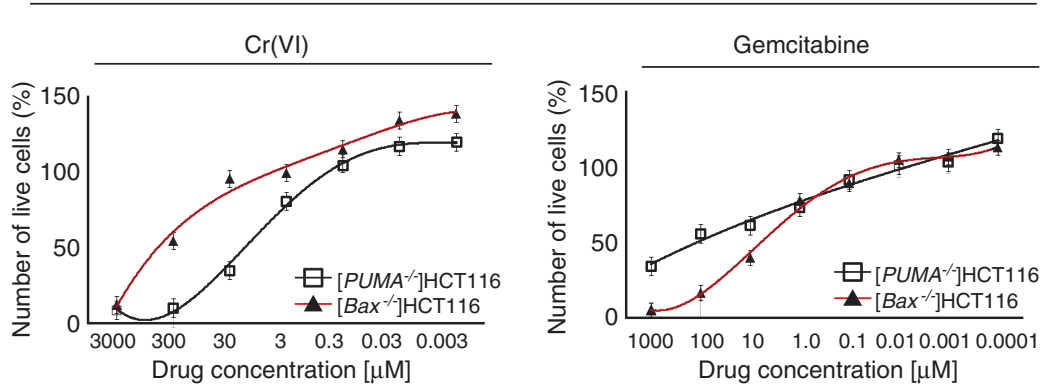

Panc-1
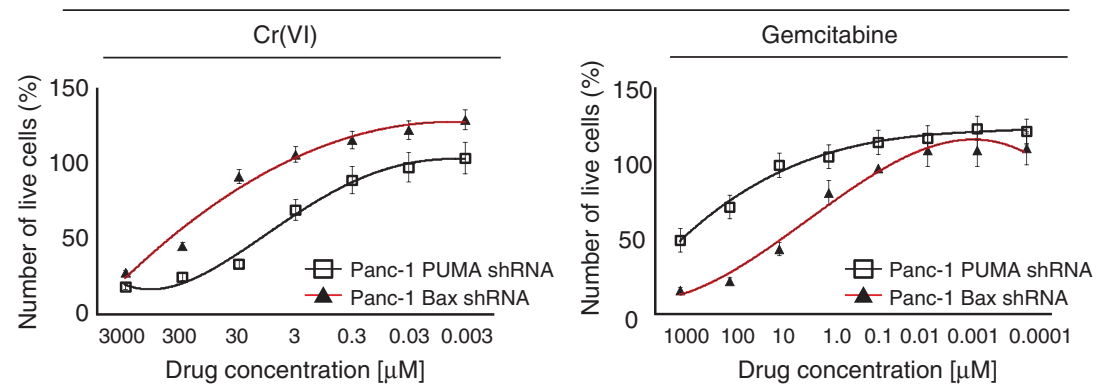

MDA-Panc-3
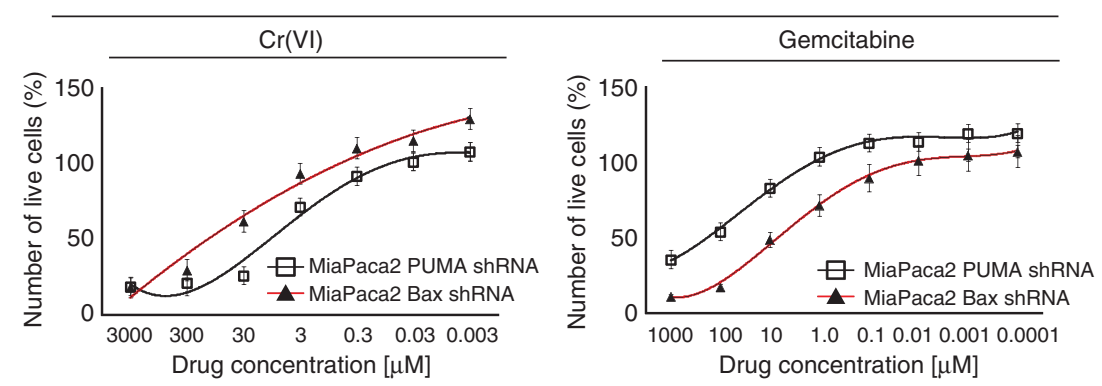

b
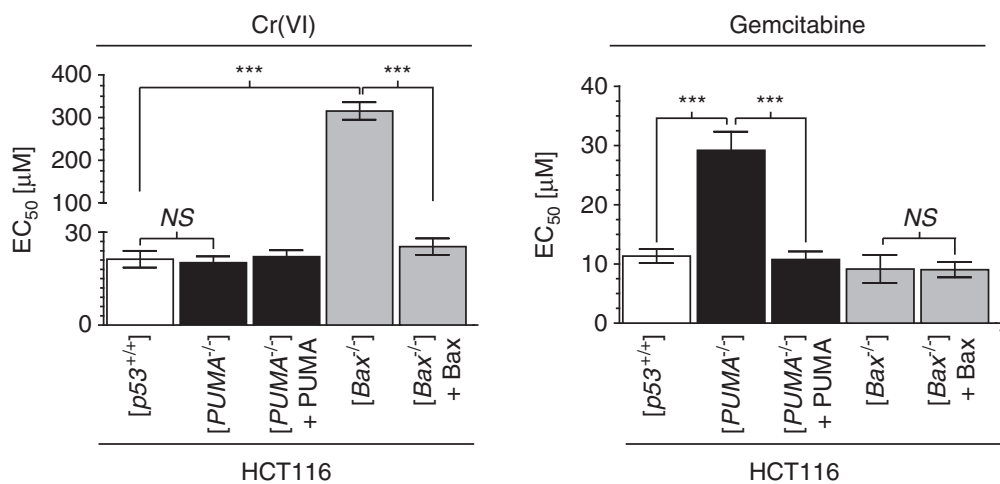

Figure 5 Gemcitabine requires PUMA to induce cell death. (a) Cells with PUMA or Bax knocked out or knocked down were exposed to gemcitabine for $72 \mathrm{~h}$ and MTS assays were conducted. Results are mean \pm S.D.; ${ }^{* \star} P<0.0001,{ }^{*} P<0.05$. Each assay was conducted in triplicate, $N=3$. (b) MTS dose studies were repeated $24 \mathrm{~h}$ post transient transfection $(5 \mu \mathrm{g})$ of either the PUMA or Bax expression plasmid. $N=3$. Results are mean \pm S.D.; ${ }^{* *} P<0.0001$, NS, not significant

patients had undergone any other form of disease management (chemo- or radio-therapy) prior to the surgical removal of the tumour mass. Noticeably (Figure 7a), we observed significantly higher levels of p53 in our colon tumour samples and little to no p53 in the matched normal colon tissue raising the hypothesis that targeting this highly stabilised p53 within these tumours could promote significant tumour regression. (Due to the nature of pancreatic Whipple surgery, we were unable to conduct this analysis for our pancreatic samples). As predicted, based on the high p53 protein expression, we detected considerably higher $p 21,14-3-3 \sigma$ and Bax expression in the colon tumour tissue compared with the matched normal colon tissue samples (Figure 7b). This gene expression profile was also noted for our pancreatic tumour samples. Despite the disparity in total p53 protein levels, both the colon and pancreatic tumour samples show similar levels of PUMA 

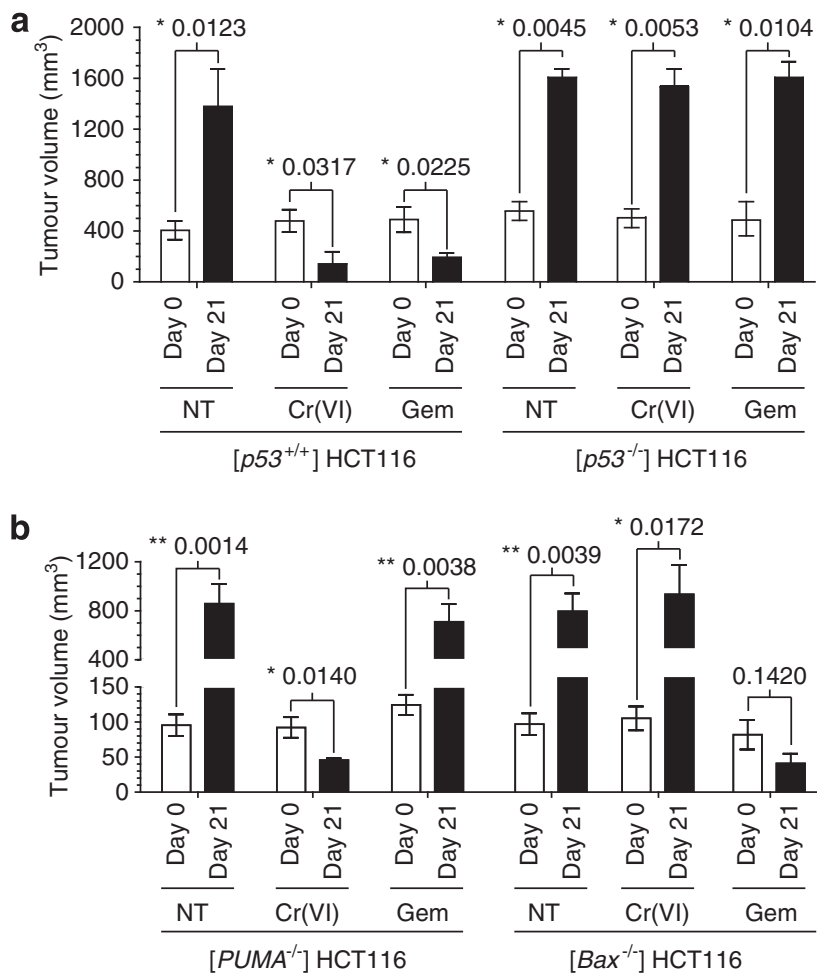

C

$\left[p 53^{+/+}\right]$HCT116

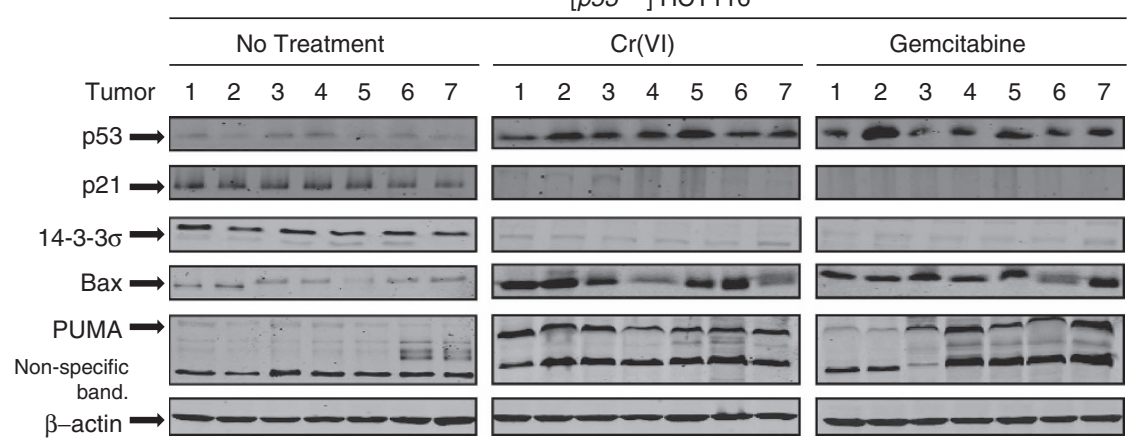

Figure 6 Gemcitabine-dependent tumour regression correlates with PUMA status. (a) Subcutaneous $\left[p 53^{+/+}\right.$] or $\left[p 53^{-/-}\right.$] HCT116 tumours were grown in the right flanks of 8-week-old male NOD/SCID mice. Palpable tumours were injected on day 1 and day 4 . Tumours were measured thrice weekly and collected 21 days post treatment or when tumours reached over $1200 \mathrm{~mm}^{3}$ volume. Seven animals were used per group. $P$-values are indicated for each group. (b) Studies, as described in a, were repeated using the matched $\left[P_{U M A}{ }^{-1-}\right]$ or $\left[\mathrm{Bax}^{-/-}\right] \mathrm{HCT} 116$ cell lines. $N=7$. (c) Tumours from a were collected 21 days post treatment and homogenized. Samples were analyzed by immunoblotting for total $\mathrm{p} 53, \mathrm{p} 21,14-3-3 \sigma$, Bax, PUMA and $\beta$-actin

expression compared with matched normal tissues. To determine whether the gene expression within these matched samples correlated with protein levels, we conducted immunoblot analysis for HIF-1 $\alpha$ (a marker of tumour hypoxia), total and ser15 phosphorylated p53, PUMA, Bax p21 and 14-3-3 $\sigma$ (Figure 7c). We observed little to no total or phosphorylated p53 in any of our normal colon tissues samples or in our extracted normal pancreatic samples. In contrast, all of the colon and pancreatic tumour samples showed significantly higher levels of total p53 and phosphorylated ser15 p53, with an average of fivefold higher levels of total p53 protein within colon cancer lysates and threefold higher in pancreatic cancer lysates (compared with matched normal tissue) (Figure 7d). The tumour samples also possessed higher levels of HIF- $1 \alpha$ typically seen in solid cancerous tissues. Consistent with the gene expression data, the tumour samples generally displayed higher levels of p21, 14-3-3 $\sigma$ and Bax compared with the matched normal tissues. In contrast, despite the significant quantity of p53 in each tumour, the levels of PUMA protein remained very low.

We questioned if the high expression of $p 21,14-3-3 \sigma$ and Bax combined with the low expression of PUMA seen in these tumour samples was due to differences in p53 binding to the promoters of these genes. The p21, PUMA and Bax biotintagged promoter sequences were generated (described in our Materials and Methods) and incubated with our lysed matched clinical samples, allowing the p53 protein to bind to these sequences. The bound p53 was then extracted and analyzed by immunoblotting, (Figure 7e). Following streptavidin pulldown, non-captured lysates (containing any unbound proteins 
(including any p53 that did not bind) were also kept and analyzed by immunoblotting. Due to the extremely low levels of total p53 protein within each normal tissue sample, there was a low amount of p53 (bound/unbound) on each of the three tested promoters. When the colon cancer tissues were similarly analyzed, we noted abundant p53 binding to the $p 21$ and Bax promoters. In contrast, despite the significant abundance of p53 protein, there was little to no p53 binding to the PUMA promoter. While the level of p53 protein differed significantly between normal and cancerous tissue (see Figure $7 d$ ), the percentage of bound p53 (from the total p53 protein pool) was similar, $\sim 60-70 \%$ for the p21 and Bax promoter sequences. Strikingly, despite high levels of the p53 protein in our colon cancer lysates, $<10 \%$ of the total protein would bind to this promoter region (Figure 7e). Therefore, expression levels of these p53 target genes appear to correlate with the capacity of p53 to bind to these promoters.

\section{Discussion}

We show that gemcitabine and chromium exposure each instigates p53-dependent apoptosis in contrast to $\gamma$-IRinduced DNA damage that mediates a potent p53-regulated cell cycle arrest response. Cells exposed to $\gamma$-IR also show elevated levels of expression of the pro-apoptotic genes (Bax, PUMA, Bid), suggesting that expression of these is a default response to DNA damage. A major difference is found in the expression of the pro-growth arrest genes $p 21$ and $14-3-3 \sigma$, where $\gamma$-IR enhances their expression (triggering arrest), whereas agents that induce cell death suppress their expression. This downregulation is a prerequisite for the induction of apoptosis as the loss/reduction of either p21 or $14-3-3 \sigma$ significantly increases cell line sensitivity to each apoptotic agent, and the combined loss of $p 21$ and 14-3-3 $\sigma$ synergistically enhances this sensitivity.

Although gemcitabine and $\mathrm{Cr}(\mathrm{VI})$ each induce p53-dependent apoptosis, their modes of action are very different. Gemcitabine mediates a transcription-dependent apoptotic response compared with $\mathrm{Cr}(\mathrm{VI})$ that instigates a transcriptionindependent apoptosis response. Although the loss of p21 or 14-3-3 $\sigma$ globally promotes/sensitizes cells to apoptosis, there is an absolute requirement to upregulate pro-apoptotic proteins for gemcitabine to trigger cell death. Subsequent gene knockout, knockdown and restoration studies revealed that the protein in question is PUMA. In contrast, chromium exposure results in the stabilization of pre-existing Bax protein that is responsible for triggering the subsequent apoptosis; PUMA is not involved in this event. It thus appears that the upregulation of Bax (and PUMA) following chromium treatment is superfluous, although Bax must be initially present prior to cellular exposure to $\mathrm{Cr}(\mathrm{VI})$ to instigate the potent apoptotic response. This is congruent with the concept that global upregulation of pro-apoptotic gene expression is a default response to any type of DNA damage that needs to be suppressed when an apoptotic outcome is undesirable. Subsequent refinement in terms of specific pathway selection, candidate protein identification and usage would depend on the nature of the damage/stress.

Our in vivo studies also showed that gemcitabine induced PUMA-dependent tumour regression and $\mathrm{Cr}(\mathrm{VI})$ mediated
Bax-dependent tumour destruction. An important caveat relates to $\mathrm{Cr}(\mathrm{VI})$ exposure. Clearly, $\mathrm{Cr}(\mathrm{VI})$ is a potent chemical and, like all currently utilized chemotherapeutic agents, when injected systemically could induce significant side effects. These were not observed following the direct intratumoural injection of this chemical, and it should also be noted that the dose used was tolerated systemically over a prolonged period of time. ${ }^{22,36}$ It is also important to note that the chemotherapeutics routinely being administered have highly toxic side effects (e.g., the cardiotoxicity following doxorubicin regimes $\left.{ }^{37,38}\right)$. What is apparent from these studies is that various agents can specifically activate different 'arms'of the p53 apoptotic response and that targeting both PUMA and Bax could be a highly viable approach (summarized in Figure 8).

The prognosis for patients with advanced pancreatic adenocarcinoma is extremely poor. Despite significant research, combination regimes with gemcitabine have yielded only a minor improvement over conventional therapies. ${ }^{39,40}$ What is clear is that in our tumour samples there was significantly higher total p53 protein. We were unable to determine whether the p53 within our tumour samples harboured any/multiple p53 mutations; however, this protein was able to bind to the $p 21$ and Bax promoters, while these tumours also displayed elevated expression of these genes. Although these promoter regions could be bound (and transcribed), there clearly was an effect upon PUMA promoter recruitment where despite the increased p53 protein, there was little to no protein binding.

At present, there is an urgent need for both new treatment options and an improved understanding of how gemcitabine mediates its anti-cancer effects. Our demonstration that gemcitabine mediates its potent anti-tumour effect via p53 and PUMA in a transcription-dependent manner explains, at least in part, why clinical results with this agent have been significantly lower than what one would have predicted. As the vast majority of human cancers harbour p53 mutations that reduce DNA-binding, a drug whose mechanism of action requires efficient upregulation of PUMA would only be useful in tumours that harbour transcriptionally active p53. This draws on a recent phase II and III clinical trial finding that gemcitabine in combination with axitinib, erlotinib or cisplatin did not dramatically improve survival for patients with advanced pancreatic cancer. ${ }^{18,41,42}$ Our clinical results show that pancreatic and colon cancer samples generally contain relatively high levels of $\mathrm{p} 21,14-3-3 \sigma$ and Bax (compared with normal tissues), high levels of total p53 protein and low levels of PUMA protein. This raises the hypothesis that the low level of PUMA could be due to alternative mechanisms (other than simply being a downstream target of p53). PUMA protein stability could be negatively affected in cancer cells compared with normal cells or other components of the cellular transcription machinery could be ablating PUMA transcription in transformed cells. This is particularly interesting when p21 and $14-3-3 \sigma$ are considered because the loss of these proteins would sensitize cancer cells to a range of different therapeutic approaches, yet p53 (either wild-type or mutant p53) is able to drive the transcription of these genes in cancer patients. This suggests a dual approach for the treatment of such cancers: stabilization of Bax coupled with suppression or inhibition of p21 and/or 14-3-3 $\sigma$. 
a

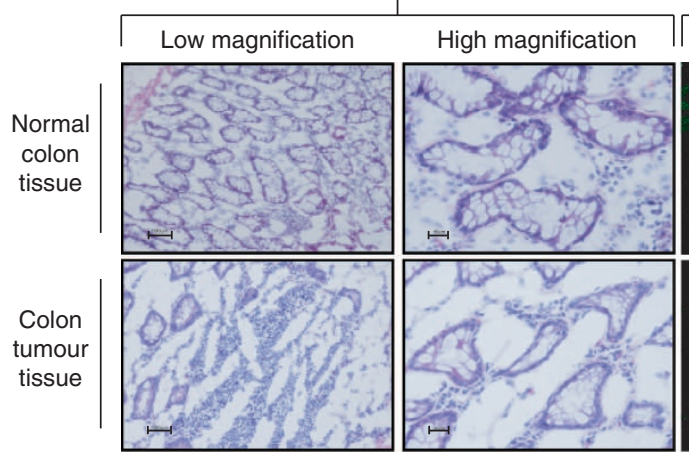

hematoxylin/eosin Immunofluorecence
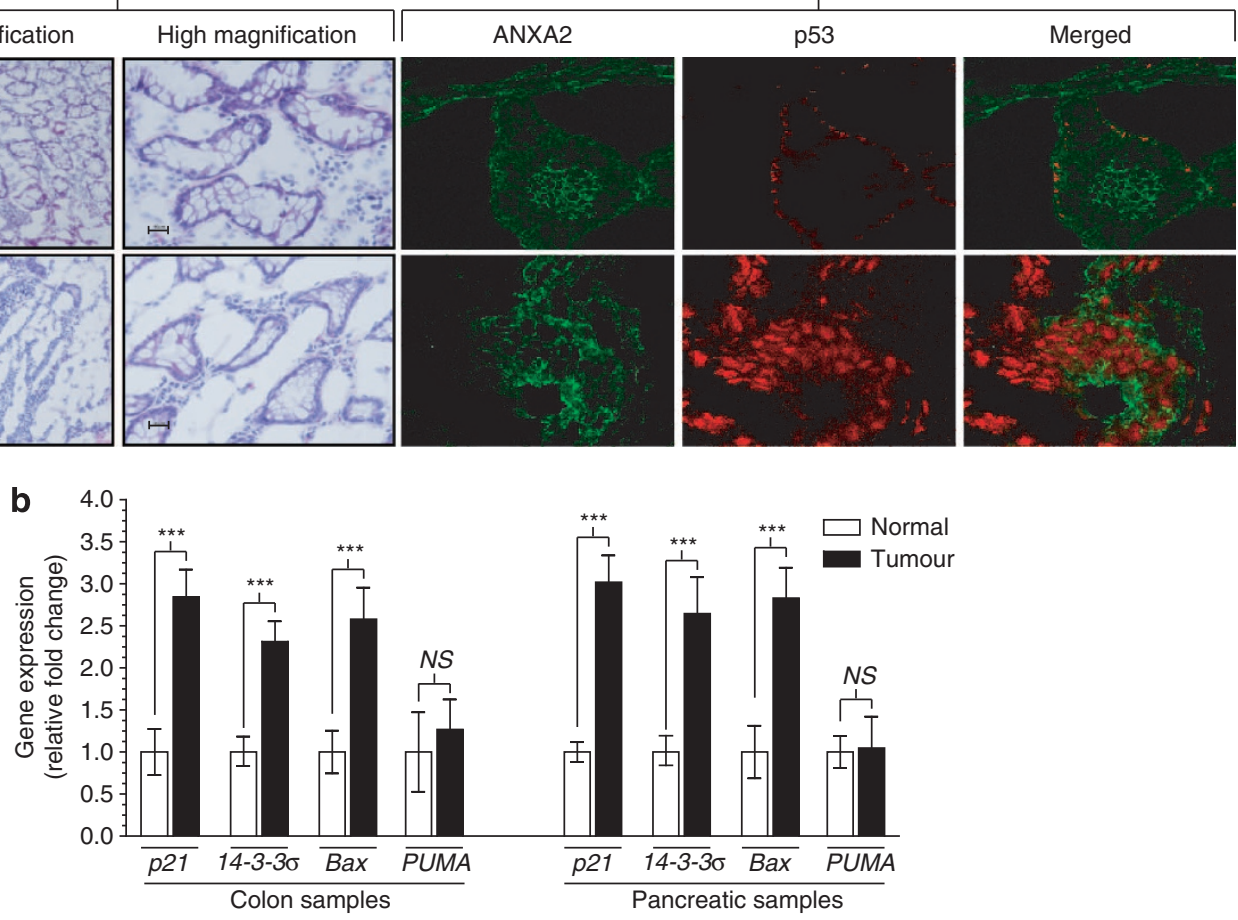

c

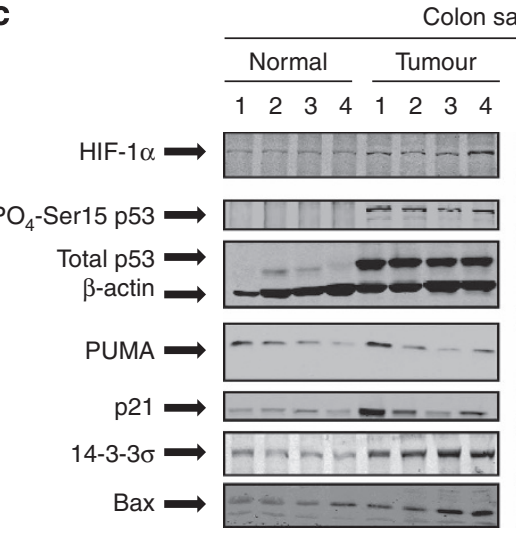

Colon samples

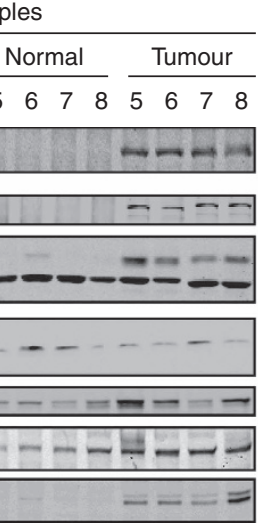

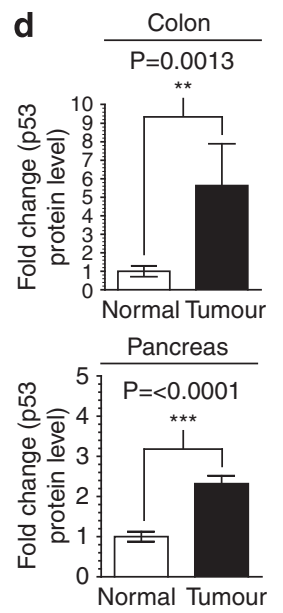

e

Promoter bound (captured) p53

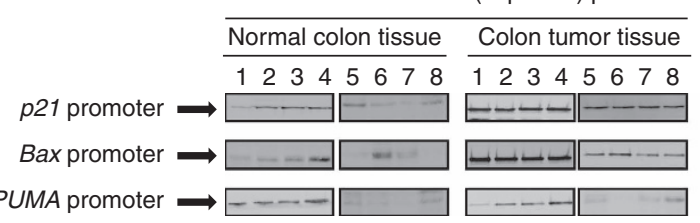
unbound p53 Normal colon tissue
12345678

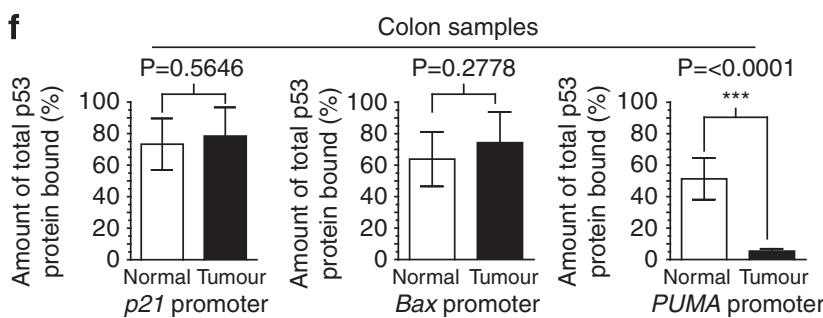


Materials and Methods

Cell lines and culture. $\left[p 53^{+/+}\right],\left[p 53^{-/-}\right],\left[p 21^{-/-}\right],\left[14-3-3 \sigma^{-/-}\right]$ $\left[\mathrm{PUMA}^{-1-}\right],\left[\mathrm{Bax}^{-/-}\right],\left[\mathrm{p} 21^{-1-} 14-3-3 \sigma^{-/-}\right],\left[\mathrm{p} 21^{-/-} \mathrm{PUMA}{ }^{-/-}\right]$and $\left[p 21^{-/-} \mathrm{Bax}^{-1-}\right] \mathrm{HCT} 116$ human colon carcinoma cells (a gift from B. Vogelstein, Johns Hopkins University), U2OS and SOAS2 human osteosarcoma (ATCC) were maintained in McCoy's 5A medium, 10\% FBS and antibiotics. Panc-1 (ATCC) and MDA-Panc-3 (a gift from N. Lemoine, originally generated by M Frazier, University of Texas) human pancreatic carcinoma cell lines were maintained in DMEM supplemented with 10\% FBS and antibiotics.

Reagents and antibodies. Total cell lysate was prepared from cells (50 mM Tris- $\mathrm{HCl}$ pH 7.4, 1\% NP-40, 0.5\% Na-deoxychlorate, $150 \mathrm{mM} \mathrm{NaCl}, 1 \mathrm{mM}$ EDTA, $2 \mathrm{mM} \mathrm{NaF}, 2 \mathrm{mM} \mathrm{NaVO} 4$ and $1 \times$ PIC (Sigma, St. Louis, MO, USA)) and fractionated as described in Grayson et al. ${ }^{43}$ Actinomycin $D(A c t D)$ was used at $1 \mu \mathrm{g} / \mathrm{ml}$ (Sigma, US). Antibodies against p53 (D01), p21 (C-19), 14-3-3 $\sigma$, caspase-9, tubulin and $\beta$-actin (Santa Cruz, Dallas, TX, USA), PUMA, caspase-2, caspase-3, Bax and Bcl-2 (Cell Signalling, Danvers, MA, USA). Visualization of signal was achieved using an Odyssey infrared Imaging System (Licor Bioscience, Lincoln, NE, USA). A detailed description of each antibody and the conditions used is described in our Supplementary Data.

Dose response analysis. Cells were seeded in 96-well plates at $1 \times 10^{4}$ cells per well and $24 \mathrm{~h}$ later treated with various DNA-damaging agents (gemcitabine hydrochloride (Eli Lilly \#VL7502) and $\mathrm{K}_{2} \mathrm{CrO}_{7}(\mathrm{Cr}(\mathrm{VI})$ ) (both Sigma) at the concentrations described. Cell survival was determined by CellTiter 96 Aqueous non-radioactive proliferation assay (MTS assay; Promega, Madison, WI, USA).

Quantitative real time PCR. Total RNA was extracted by using Trizol (Invitrogen, Grand Island, NY, USA). Real time PCR was performed on a Stratagene MX3000P PCR machine using the Stratagene Sybr green master mix (Stratagene, La Jolla, CA, USA). The primer sequences for measuring p21,
14-3-3 $\sigma, B c l-2, B c l-X L, B I D, B a x$, PUMA and GAPDH (Invitrogen) are described in detail in our Supplementary Data. Data analysis was carried out using the $2^{-\Delta \Delta C T}$ method described by Livak et al. ${ }^{44}$

Annexin-V analysis. Cells were treated with $10 \mu \mathrm{M}$ gemcitabine, $30 \mu \mathrm{M}$ $\mathrm{Cr}(\mathrm{VI})$ or $10 \mathrm{~Gy} \gamma-\mathrm{IR}$ and incubated for an additional $48 \mathrm{~h}$. Cells were staining for Annexin-V (BD Pharmigen, Mississauga, ON, USA) following the manufacturer's instructions.

p53-promoter binding analysis. The promoter sequences (containing the p53 responsive element) for p21 BAX and PUMA were obtained from Invitrogen with their $5^{\prime}$ biotin-tagged. Complementary, non-tagged sequences were obtained for each gene generating dsDNA sequences. dsDNA sequences were bound to streptavidin-conjugated magnetic beads generating dsDNA probes. $200 \mu \mathrm{g}$ of clinical lysate were pre-mixed with $10 \mu \mathrm{g}$ of poly(dl-dC) (Sigma) and mixed at $4^{\circ} \mathrm{C}$ for $1 \mathrm{~h}$. Samples were added to each dsDNA-bead probe and incubated at $4{ }^{\circ} \mathrm{C}$ for $1 \mathrm{~h}$ and mixed end-over-end. Both captured and non-captured lysates were isolated and analysed by SDS-PAGE electrophoresis (addressing p53-promoter recruitment).

Animal studies. Eight-week-old male NOD/SCID mice (Charles River, Wilmington, MA, USA) were divided into treatment groups $(N=7)$. Mice were injected subcutaneously with $2 \times 10^{6}$ cells in PBS. Control groups received intratumoural injections of PBS, whereas the treatment groups received 2 doses of $20 \mathrm{mg}$ per $\mathrm{kg}$ gemcitabine or $10 \mathrm{mg}$ per $\mathrm{kg} \mathrm{K}_{2} \mathrm{CrO}_{7} \mathrm{Cr}(\mathrm{VI})$ on day 1 and day 4 based on tumour weight. Tumour volume was measured thrice weekly (digital callipers) and calculated using the formula: (length $\times$ width $\times$ width)/3.142, where length is the larger diameter of the tumour $(\mathrm{mm})$. Animals were culled by $\mathrm{CO}_{2}$ asphyxiation and tumours excised for analysis. The experimental design was vetted by the Dalhousie University Ethical Committee and met all standards required by the Canadian authority for animal welfare.

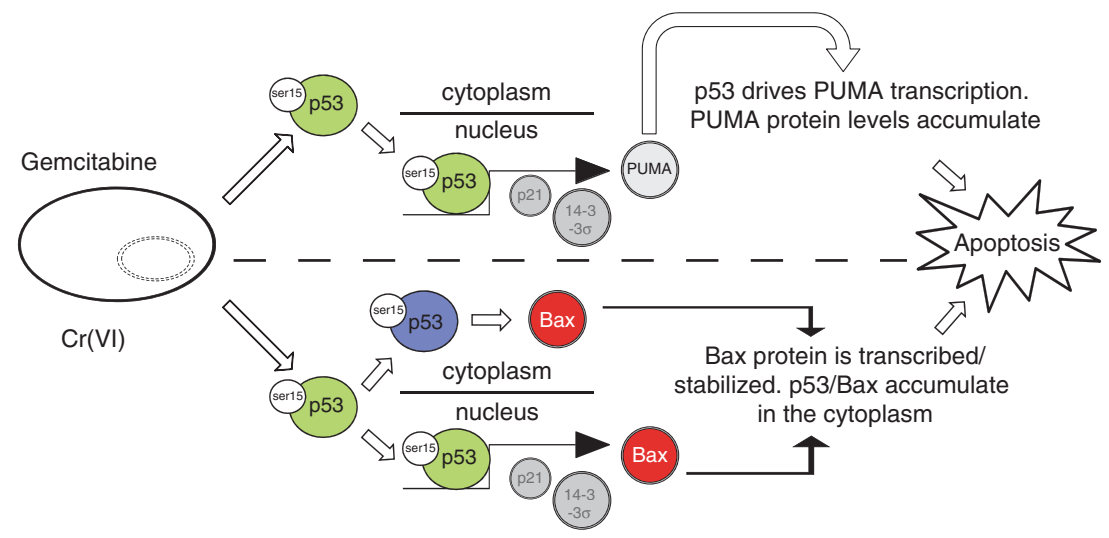

Figure 8 Proposed 'arms' of the p53 apoptotic response. Under apoptotic conditions (e.g. gemcitabine or CrVI)), p53 is activated and accumulates. Following gemcitabine exposure, p53 accumulation is predominately nuclear inducing the transcription of PUMA (in addition to Bax and other p53-regulated genes). Following the accumulation of PUMA protein, there is a significant induction of PUMA-dependent/transcription-dependent apoptosis. In contrast, $\mathrm{Cr}(\mathrm{VI})$ exposure induces p53 accumulation (and subsequent transcription of Bax and PUMA); however, this is not a crucial requirement to induce apoptosis as there is a significant accumulation of p53 (and Bax) protein within the cytoplasm of $\mathrm{Cr}(\mathrm{VI})$-exposed cells. As a result, $\mathrm{Cr}(\mathrm{VI})$ induces a potent Bax-dependent/transcription-independent apoptotic response characterized by p53 and BAx protein accumulation in the cytoplasm of exposed cells. Regardless of the crucial effector protein, both modalities ablate $p 21$ and 14-3-3 $\sigma$ expression, priming the cell to induce apoptosis

Figure 7 Primary colon and pancreatic tumours display elevated p53 and attenuated PUMA protein expression. (a) H\&E staining was conducted following surgical removal of colon tumour and matched normal tissue. Scale bars (low magnification) indicate $100 \mu \mathrm{m}$ and $40 \mu \mathrm{m}$ (high magnification). Immunofluorescence staining was carried out from snap-frozen tumour tissue immediately after surgical removal. Sections were stained for ANXA2 (cell surface marker) and p53. (b) Colon ( $N=8)$ and pancreatic $(N=6)$ tumour samples (including matched normal tissue) were surgically removed. qRT-PCR was conducted for p21, 14-3-3 $\sigma$, Bax, PUMA and GAPDH in quadruplicate (c) Colon tumour, pancreatic tumour and matched normal tissue were surgically removed and homogenized, and proteins were extracted. Samples (100 $\mu \mathrm{g}$ ) were analyzed by immunoblotting for HIF- $1 \alpha$, Phospho-Ser15 p53, total p53, $\beta$-actin, p21 14-3-3 $\sigma$, PUMA and Bax. (d) The average amount of total p53 protein was quantified and the mean average \pm S.D. $(N=8$ and 6 , respectively) was plotted for both of our normal and cancer samples. (e) Fifty microgram of the total protein extract from $\mathbf{c}$ was incubated with our generated, specific biotinylated promoter sequences for the p21, Bax or PUMA genes addressing p53 recruitment/binding. Following capture, protein/DNA complexes were separated using streptavidin beads (Invitrogen). Proteins were removed, denatured and analysed by immunobotting for total p53. Non-captured/promoter bound p53 protein was similarly analyzed. (f) Each sample (bound/unbound p53) from each sample (normal or colon cancer) was quantified and the percentage of bound p53 protein was calculated. The mean average percentage \pm S.D. was plotted and $P$-values comparing the percentage bound between normal/cancer samples was calculated 
Clinical sample collection. Core tumour samples of colon carcinoma were obtained from patients with colon cancer at the time of their surgery. At the time, a section of matched normal colon tissue was extracted adjacent to the tumour site. Pancreatic tumour tissue (and matched normal tissue) was obtained during surgery (Whipple protocol). Patient consent and ethical approval was obtained for each procedure from the Research Ethics Board, (VG Hospital, Halifax, Nova Scotia, Canada)

\section{Conflict of Interest}

The authors declare no conflict of interest.

Acknowledgements. We would like to thank Dr. B Vogelstein (John Hopkins University, Baltimore, MD) for kindly providing us with our panel of matched HCT116 cell lines, the PUMA and Bax expression plasmids and Professor N Lemoine (Barts Cancer Institute, Queens Mary University) for providing MDA-Panc-3 cells (originally generated by Dr. M Frazier, University of Texas MD Anderson Cancer Center). $\mathrm{RH}$ is the recipient of a Fundação para a Ciência e a Tecnologia (FCT) 2012 research grant no. SFRH/BPD/84634/2012. PAM received funding from the European Union Seventh Framework Programme (FP7/2007-2013) under grant agreement no. PCOFUND-GA-2009-246542 and from the Foundation for Science and Technology of Portugal. This research is supported by the Canadian Institute of Health Research (to PWKL).

1. Vogelstein B, Kinzler KW. p53 function and dysfunction. Cell 1992; 70: 523-526.

2. Waldman T, Kinzler KW, Vogelstein B. p21 is necessary for the p53-mediated G1 arrest in human cancer cells. Cancer Res 1995; 55: 5187-5190.

3. Wahl GM, Carr AM. The evolution of diverse biological responses to DNA damage: insights from yeast and p53. Nat Cell Biol 2001; 3: E277-E286.

4. Xue W, Zender L, Miething C, Dickins RA, Hernando E, Krizhanovsky V et al. Senescence and tumour clearance is triggered by p53 restoration in murine liver carcinomas. Nature 2007; 445: 656-660.

5. Pietenpol JA, Tokino T, Thiagalingam S, el-Deiry WS, Kinzler KW, Vogelstein B. Sequence-specific transcriptional activation is essential for growth suppression by p53. Proc Natl Acad Sci USA 1994; 91: 1998-2002.

6. Zupnick A, Prives C. Mutational analysis of the p53 core domain L1 loop. J Biol Chem 2006; 281: 20464-20473

7. Qian H, Wang T, Naumovski L, Lopez CD, Brachmann RK. Groups of p53 target genes involved in specific p53 downstream effects cluster into different classes of DNA binding sites. Oncogene 2002; 21: 7901-7911.

8. Nakano K, Vousden KH. PUMA, a novel proapoptotic gene, is induced by p53. Mol Cell 2001; 7: 683-694.

9. Yu J, Wang Z, Kinzler KW, Vogelstein B, Zhang L. PUMA mediates the apoptotic response to p53 in colorectal cancer cells. Proc Natl Acad Sci USA 2003; 100: 1931-1936.

10. Chipuk JE, Green DR. Cytoplasmic p53: bax and forward. Cell Cycle 2004; 3: 429-431.

11. Chipuk JE, Green DR. p53's believe it or not: lessons on transcription-independent death. J Clin Immunol 2003; 23: 355-361.

12. Mihara M, Erster S, Zaika A, Petrenko O, Chittenden T, Pancoska $P$ et al. $p 53$ has a direct apoptogenic role at the mitochondria. Mol Cell 2003; 11: 577-590.

13. Chipuk JE, Kuwana T, Bouchier-Hayes L, Droin NM, Newmeyer DD, Schuler M et al. Direct activation of Bax by p53 mediates mitochondrial membrane permeabilization and apoptosis. Science 2004; 303: 1010-1014.

14. Erster S, Mihara M, Kim RH, Petrenko O, Moll UM. In vivo mitochondrial p53 translocation triggers a rapid first wave of cell death in response to DNA damage that can precede p53 target gene activation. Mol Cell Biol 2004; 24: 6728-6741.

15. Leu JI, Dumont P, Hafey M, Murphy ME, George DL. Mitochondrial p53 activates Bak and causes disruption of a Bak-Mcl1 complex. Nat Cell Biol 2004; 6: 443-450.

16. Abbruzzese $\mathrm{JL}$. New applications of gemcitabine and future directions in the management of pancreatic cancer. Cancer 2002; 95(4 Suppl): 941-945.

17. Macdonald JS. Clinical overview: adjuvant therapy of gastrointestinal cancer. Cancer Chemother Pharmacol 2004; 54(Suppl 1): S4-11.

18. Okusaka T, Ishii H, Funakoshi A, Ueno H, Furuse J, Sumii T. A phase $1 / / l$ study of combination chemotherapy with gemcitabine and 5 -fluorouracil for advanced pancreatic cancer. Jpn J Clin Oncol 2006; 36: 557-563.

19. Marsman DS, Barrett JC. Apoptosis and chemical carcinogenesis. Risk Anal 1994; 14: 321-326.

20. O'Brien TJ, Fornsaglio JL, Ceryak S, Patierno SR. Effects of hexavalent chromium on the survival and cell cycle distribution of DNA repair-deficient S. cerevisiae. DNA Repair (Amst) 2002; 1: 617-627.
21. Salnikow K, Zhitkovich A, Costa M. Analysis of the binding sites of chromium to DNA and protein in vitro and in intact cells. Carcinogenesis 1992; 13: 2341-2346.

22. O'Brien TJ, Ceryak S, Patierno SR. Complexities of chromium carcinogenesis: role of cellular response, repair and recovery mechanisms. Mutat Res 2003; 533: 3-36.

23. Laronga C, Yang HY, Neal C, Lee MH. Association of the cyclin-dependent kinases and 14-3-3 sigma negatively regulates cell cycle progression. J Biol Chem 2000; 275: 23106-23112.

24. Hill R, Leidal AM, Madureira PA, Gillis LD, Cochrane HK, Waisman DM et al. Hypersensitivity to chromium-induced DNA damage correlates with constitutive deregulation of upstream p53 kinases in p21-/- HCT116 colon cancer cells. DNA Repair (Amst) 2008; 7 : 239-252.

25. Javelaud D, Besancon F. Inactivation of p21WAF1 sensitizes cells to apoptosis via an increase of both p14ARF and p53 levels and an alteration of the Bax/Bcl-2 ratio. J Biol Chem 2002; 277: 37949-37954.

26. Taylor WR, Stark GR. Regulation of the G2/M transition by p53. Oncogene 2001; 20: 1803-1815.

27. Hermeking H, Lengauer C, Polyak K, He TC, Zhang L, Thiagalingam S et al. 14-3-3 sigma is a p53-regulated inhibitor of G2/M progression. Mol Cell 1997; 1: 3-11.

28. Chan TA, Hermeking H, Lengauer C, Kinzler KW, Vogelstein B. 14-3-3Sigma is required to prevent mitotic catastrophe after DNA damage. Nature 1999; 401: 616-620.

29. Hill R, Leidal AM, Madureira PA, Gillis LD, Waisman DM, Chiu A et al. Chromium-mediated apoptosis: involvement of DNA-dependent protein kinase (DNA-PK) and differential induction of p53 target genes. DNA Repair (Amst) 2008; 7: 1484-1499.

30. Hill R, Madureira PA, Waisman DM, Lee PW. DNA-PKCS binding to p53 on the p21WAF1/CIP1 promoter blocks transcription resulting in cell death. Oncotarget 2011; 2: 1094-1108.

31. Kastan MB, Onyekwere O, Sidransky D, Vogelstein B, Craig RW. Participation of $p 53$ protein in the cellular response to DNA damage. Cancer Res 1991; 51(23 Pt 1): 6304-6311.

32. Price BD, Youmell MB. The phosphatidylinositol 3-kinase inhibitor wortmannin sensitizes murine fibroblasts and human tumor cells to radiation and blocks induction of p53 following DNA damage. Cancer Res 1996; 56: 246-250.

33. Suzuki A, Tsutomi Y, Akahane K, Araki T, Miura M. Resistance to Fas-mediated apoptosis: activation of caspase 3 is regulated by cell cycle regulator p21WAF1 and IAP gene family ILP. Oncogene 1998; 17: 931-939.

34. Hollstein M, Sidransky D, Vogelstein B, Harris CC. p53 mutations in human cancers. Science 1991; 253: 49-53.

35. Erster S, Slade N, Moll UM. Mutational analysis of p53 in human tumors: direct DNA sequencing and SSCP. Methods Mol Biol 2003; 234: 219-230.

36. Singh J, Carlisle DL, Pritchard DE, Patierno SR. Chromium-induced genotoxicity and apoptosis: relationship to chromium carcinogenesis (review). Oncol Rep 1998; 5 1307-1318.

37. Octavia Y, Tocchetti CG, Gabrielson KL, Janssens S, Crijns HJ, Moens AL. Doxorubicininduced cardiomyopathy: from molecular mechanisms to therapeutic strategies. J Mol Cell Cardiol 2012; 52: 1213-1225.

38. Ewer MS, Ewer SM. Cardiotoxicity of anticancer treatments: what the cardiologist needs to know. Nat Rev Cardiol 2010; 7: 564-575.

39. Moore MJ, Goldstein D, Hamm J, Figer A, Hecht JR, Gallinger S et al. Erlotinib plus gemcitabine compared with gemcitabine alone in patients with advanced pancreatic cancer: a phase III trial of the National Cancer Institute of Canada Clinical Trials Group. $J$ Clin Oncol 2007; 25: 1960-1966.

40. Van $\mathrm{CE}$, Verslype $\mathrm{C}$, Grusenmeyer PA. Lessons learned in the management of advanced pancreatic cancer. J Clin Oncol 2007; 25: 1949-1952.

41. Okusaka T, Furuse J, Funakoshi A, loka T, Yamao K, Ohkawa S et al. Phase II study of erlotinib plus gemcitabine in Japanese patients with unresectable pancreatic cancer. Cancer Sci 2011; 102: 425-431.

42. Kindler HL, loka T, Richel DJ, Bennouna J, Letourneau R, Okusaka T et al. Axitinib plus gemcitabine versus placebo plus gemcitabine in patients with advanced pancreatic adenocarcinoma: a double-blind randomised phase 3 study. Lancet Oncol 2011; 12: 256-262.

43. Grayson S, Elias PM. Human epidermal proteolipids: isolation, partial characterization, and subcellular localization. J Invest Dermatol 1988; 90: 185-192.

44. Livak KJ, Schmittgen TD. Analysis of relative gene expression data using real-time quantitative PCR and the 2(-Delta Delta $C(T))$ Method. Methods 2001; 25: 402-408.

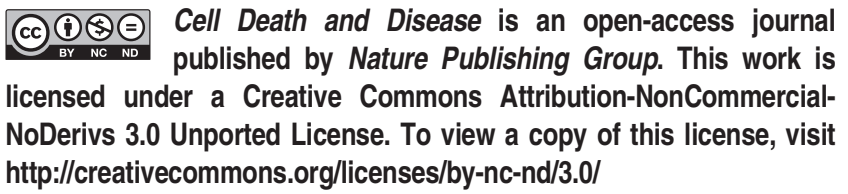

